\title{
Crescimento inicial de espécies de Urochloa em função da profundidade de semeadura
}

\author{
Fenelon Lourenço de Sousa Santos ${ }^{1}$, Willany Rayany Formiga Melo ${ }^{1}$, Paulo Henrique \\ Moreira Coelho ${ }^{1}$, Cleiton Gredson Sabin Benett ${ }^{2}$, Marciane Cristina Dotto ${ }^{3}$

\footnotetext{
${ }^{1}$ Universidade Estadual de Goiás, Unidade Universitária de Ipameri, Ipameri, Goiás, Brasil. E-mail: lourenco_dm@hotmail.com, willanyrayany@gmail.com,phmoreiracoelho@yahoo.com.br

${ }^{2}$ Instituto Federal Goiano, Campus de Urutaí, Urutaí, Goiás, Brasil. E-mail: cbenett@ hotmail.com

${ }^{3}$ Universidade Federal do Tocantins, Gurupi, Tocantins, Brasil. E-mail: marcydotto@uft.edu.br
}

Recebido: 01/10/2015; Aceito: 03/11/2015

\section{RESUMO}

A utilização de plantas de cobertura é uma prática cada vez mais adotada por produtores que utilizam o sistema plantio direto (SPD). No entanto, a profundidade de semeadura tem grande importância na implantação de consórcios de culturas anuais de grãos com gramíneas forrageiras, por influenciar diretamente a emergência das plântulas, podendo ser um fator decisivo para o sucesso do sistema de integração lavoura-pecuária (ILP). Objetivou-se, com esse trabalho, avaliar o crescimento inicial de plântulas de Urochloa brizantha cv. BRS Piatã, $U$. brizantha cv. BRS Paiaguás e $U$. ruziziensis em razão da profundidade de semeadura. O delineamento experimental utilizado foi inteiramente casualizado, em esquema fatorial $3 \times 5$, sendo três espécies e cinco profundidades $(0,2,4$, 6 e $8 \mathrm{~cm}$ ), com três repetições. Foram avaliados: o índice de velocidade de emergência, a porcentagem de emergência de plântulas, produção de fitomassa verde e seca da parte aérea e das raízes e a razão de massa radicular. As espécies $U$. brizantha cv. Piatã, $U$. brizantha cv. Paiaguás e $U$. ruziziensis apresentam um maior acúmulo de fitomassa seca, quando semeados a 2,10, 3,61 e 3,67 cm, respectivamente, sendo essas profundidades recomendadas como ideais para semeadura.

Palavras-chave: Urochloa brizantha, Urochloa ruziziensis, integração lavoura-pecuária, emergência das plântulas.

\section{Initial growth of Urochloa species as affected by sowing depth}

\begin{abstract}
The use of cover crops is a practice adopted by producers using the no-till system. However, the depth of sowing is very important for the sowing of intercropping forage grasses with annual grain crops by directly influence seedling emergence and can be a decisive factor for the success of integrated crop-livestock system. This study aimed to evaluate the effect of depth of seeding on initial growth of Urochloa brizantha cv. BRS Piata, Urochloa brizantha cv. BRS Paiaguás and Urochloa ruziziensis. The experimental design was completely randomized in a $3 \times 5$ factorial, with three forage species and five depths $(0,2,4,6$ and $8 \mathrm{~cm})$, with three replications. Emergency rate index, percentage of seedling emergence, fresh and dry matter production of shoots and roots, and root mass ratio was measured. The $U$. brizantha cv. Piata, U. brizantha cv. Paiaguás and $U$. ruziziensis species have a higher accumulation of dry matter, when sown at $2.10,3.61$ and $3.67 \mathrm{~cm}$, respectively, and these depths are recommended as ideal for sowing.
\end{abstract}

Key words: Urochloa brizantha, Urochloa ruziziensis, integrated crop-livestock, plant emergence. 


\section{Introdução}

O sistema plantio direto (SPD) é apontado como um dos principais responsáveis pelo significativo aumento da produtividade e continuidade da exploração agrícola dos solos brasileiros. Contudo, para a implantação e condução desse sistema, de maneira sustentável, é imprescindível, além do não revolvimento do solo, a rotação de culturas, de forma a proporcionar a manutenção permanente de quantidade mínima de palha na superfície do solo (CRUSCIOL et al., 2010).

Pesquisas têm reportado a viabilidade técnicoeconômica do uso da consorciação de milho com espécies forrageiras (RICHETTI, 2012, GARCIA et al., 2012); portanto, houve crescente demanda de sementes de forrageiras, especialmente de Urochloa spp. Esse aumento na demanda se deve ao fato da crescente utilização dos sistemas de Integração Lavoura-Pecuária (ILP).

Dentre os principais problemas para o adequado estabelecimento do estande das espécies forrageiras, a profundidade inadequada da semeadura constitui em um dos destaques para o insucesso. Quando semeadas em profundidade superiores a recomendada pode ocorrer a germinação das sementes, sem haver à emergência das plântulas devido à baixa quantidade de reservas nas sementes que as impede de atingir a superfície do solo. Quando ficam expostas na superfície do solo, as sementes têm maior dificuldade para absorver água devido a menor superfície de contato com o solo e consequentemente interferindo negativamente no processo de germinação (DIAS-FILHO, 2012).

A profundidade de semeadura tem grande importância também na implantação de consórcios de culturas anuais destinadas à produção de grãos com gramíneas forrageiras. Pode-se estabelecer uma vantagem competitiva às culturas anuais ao efetuar a semeadura das gramíneas forrageiras em maior profundidade do solo, uma vez que as gramíneas possuem mesocótilo (IKEDA et al., 2013). Esse mecanismo de adaptação à semeadura profunda se alonga para elevar o meristema apical até a superfície do solo, o que aumenta o tempo para ocorrer à emergência, diminuindo a competição com a cultura consorciada.

Apesar dessas informações, há necessidade de ampliar o conhecimento sobre a influência da profundidade de semeadura na emergência de plântulas de Urochloa spp. e que poderiam ser empregados no estabelecimento em consórcio com as culturas anuais (PACHECO et al., 2010; IKEDA et al., 2013).

O cultivar BRS Paiaguás é uma cultivar de Urochloa brizantha que foi selecionada para alta produtividade, vigor e produção de sementes, apresentando alto potencial de produção na estação seca, mostrando ser uma excelente alternativa de pastejo durante a estação seca em relação a $U$. brizantha cv. Piatã. Além, destas características, o cultivar é adaptado a solos de fertilidade média, apresentando boas respostas à adubação (VALLE et al., 2013). Tais características denotam o potencial deste cultivar com cultura de cobertura para o sistema de integração lavourapecuária, visando uma pastagem de excelente qualidade na entressafra e permitindo, assim, maiores ganhos na atividade pecuária.

Este estudo teve como objetivo avaliar a emergência e o crescimento inicial de plântulas de Urochloa brizantha cv. BRS Piatã, $U$. brizantha cv. BRS Paiaguás e $U$. ruziziensis semeadas em diferentes profundidades.

\section{Material e Métodos}

$\mathrm{O}$ experimento foi realizado durante o mês de maio de 2014, em casa de vegetação com iluminação natural na Universidade Estadual de Goiás, em Ipameri, Goiás

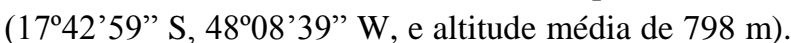
A média da temperatura máxima e mínima foi de $32,5 \mathrm{e}$ $14,0^{\circ} \mathrm{C}$, respectivamente. $\mathrm{O}$ experimento foi irrigado uma vez por dia, durante todos os dias até a conclusão do ensaio. O solo utilizado foi um Latossolo VermelhoAmarelo coletado na camada de $0-20 \mathrm{~cm}$. O solo apresentou as seguintes características: $\mathrm{pH} \mathrm{em} \mathrm{CaCl}_{2} \mathrm{de}$ 4,9; $\mathrm{Ca}, \mathrm{Mg}, \mathrm{Al}$ e $\mathrm{H}+\mathrm{Al}$ de 1,$5 ; 0,6 ; 0,1 ; 3,6 \mathrm{cmol}_{\mathrm{c}} \mathrm{dm}^{-3}$, respectivamente; $\mathrm{K}$ e $\mathrm{P}$ de 59,0 e $3,7 \mathrm{mg} \mathrm{dm}^{-3}$, respetivamente; CTC de 5,6 $\mathrm{cmol}_{\mathrm{c}} \mathrm{dm}^{-3} ; 38,5 \%$ de saturação de bases; $25,0 \mathrm{~g} \mathrm{dm}^{-3}$ de matéria orgânica; teores de areia, silte e argila de 570,90 e $340 \mathrm{~g} \mathrm{~kg}^{-1}$, respectivamente.

$\mathrm{O}$ delineamento experimental utilizado foi o de blocos casualizados, em esquema fatorial $3 \times 5$, com três repetições. Os tratamentos resultaram a combinação de três forrageiras (Urochloa brizantha cv. BRS Piatã, Urochloa brizantha $c v$. BRS Paiaguás e Urochloa ruziziensis) e cinco profundidades de semeadura $(0,2$, 4,6 e $8 \mathrm{~cm}$ ). Foram utilizadas sementes puras viáveis de cada material.

A semeadura foi realizada em vasos de polietileno contendo $2,7 \mathrm{dm}^{3}$ de solo. Utilizou-se uma régua graduada para medir a lateral do vaso, depositando o solo até a altura estipulada, depositando 50 sementes e completando o restante do vaso com solo.

Foram realizadas as seguintes avaliações: Índice de velocidade de emergência (IVE): registrou-se diariamente o número de plântulas emergidas, com parte aérea formada, até $\mathrm{o} 17^{\circ}$ dia, quando houve estabilização da emergência, e este foi calculado pela fórmula proposta por Maguire (1962): $\operatorname{IVE}=\mathrm{E}_{1} / \mathrm{N}_{1}+$ $\mathrm{E}_{2} / \mathrm{N}_{2}+\ldots+\mathrm{E}_{\mathrm{N}} / \mathrm{N}_{\mathrm{N}}$; onde, IVE é o índice de velocidade de emergência; $E_{1}$, E2, e $E_{N}$ o número de plântulas normais computadas no primeiro, segundo e no último dia de contagem. $\mathrm{N}_{1}, \mathrm{~N}_{2}$, e $\mathrm{N}_{\mathrm{N}}$ é o número de dias da 
semeadura à primeira, segunda e última contagem, respectivamente.

Emergência de plântulas: foi obtido pela razão entre o número total de plântulas emergidas e a quantidade de sementes utilizadas, calculando-se a porcentagem de plantas emergidas.

Fitomassa verde: Ao final do teste de IVE, todas as plantas dos vasos foram retiradas e lavadas em água corrente, posteriormente foram separadas em parte aérea e raízes e pesadas para a obtenção da fitomassa verde.

Fitomassa seca: Após a pesagem da fitomassa verde, a parte aérea e as raízes foram secas em estufa de circulação de ar forçada por 72 horas à $70^{\circ} \mathrm{C}$, obtendo a fitomassa seca utilizando balança de precisão de $0,005 \mathrm{~g}$.

Razão de massa radicular: foi obtida pela razão entre os valores de fitomassa seca das raízes e os valores da fitomassa seca total.

Os dados do índice de velocidade de emergência, fitomassa verde e seca foram transformados em $\sqrt{(\mathrm{x}+0,5)}$, e os dados da emergência de plântulas expressos em porcentagens foram transformados em arco seno $\sqrt{\mathrm{x} / 100}$ sendo posteriormente submetidos a análise de variância ao nível de significância de $5 \%$ e quando significativos foram submetidos à análise de regressão pelo programa estatístico Assistat 7.6.

\section{Resultados e Discussão}

$O$ índice de velocidade de emergência (IVE) e a porcentagem de emergência avaliados apresentaram interação entre os fatores espécies de Urochloa e profundidade de semeadura. A análise de regressão para o IVE e porcentagem de emergência de plântulas adequaram-se a equações quadráticas (Figura 1).

As espécies apresentaram comportamentos distintos quanto ao IVE apresentando maiores valores quando semeadas a 2,68, 3,74 e 3,71 cm para as espécies de $U$. brizantha cv. BRS Piatã, $U$. brizantha cv. BRS Paiaguás, e $U$. ruziziensis, respectivamente. Esse fato pode estar relacionado as diferentes necessidades intrínsecas de cada espécie para a germinação e emergência.

Os maiores valores de porcentagem de emergência para $U$. brizantha cv. BRS Piatã, $U$. brizantha $\mathrm{cv}$. BRS Paiaguás, e $U$. ruziziensis foram obtidos quando as forrageiras foram semeadas a 2,87, 3,71 e 3,78 cm de profundidade, respectivamente (Figura 1B). Nenhuma das espécies apresentaram emergência quando as sementes foram semeadas a $8 \mathrm{~cm}$ de profundidade, o que sugere a inviabilidade de qualquer das espécies para essa profundidade de semeadura.

Todas as espécies apresentaram porcentagem de emergência inferior quando foram semeadas sobre a superfície do solo. Isso ocorreu devido ao excesso de insolação e desidratação das sementes na semeadura superficial, como reportado por Foloni et al. (2009). Além disso, quando dispostas sobre o solo, as sementes apresentam uma menor superfície de contato com o solo, o que, pode comprometer o processo de embebição das sementes, prejudicando o processo de germinação.

A análise de variância para a produção de fitomassa verde e seca da parte aérea das plântulas apresentaram interação significativa entre as espécies avaliadas e profundidade de semeadura, ajustando-se as equações quadráticas (Figuras 2).

A Urochloa brizantha cv. BRS Piatã apresentou maior produção de fitomassa verde quando semeada a $2,03 \mathrm{~cm}$ de profundidade, comportamento que demonstra sua maior adaptabilidade para cultivos mais superficiais. Urochloa brizantha cv. BRS Paiaguás e Urochloa ruziziensis apresentaram maiores produções de fitomassa verde nas profundidades de 3,58 e $3,55 \mathrm{~cm}$ respectivamente, demonstrando a possibilidade de cultivos mais profundos para essas espécies.
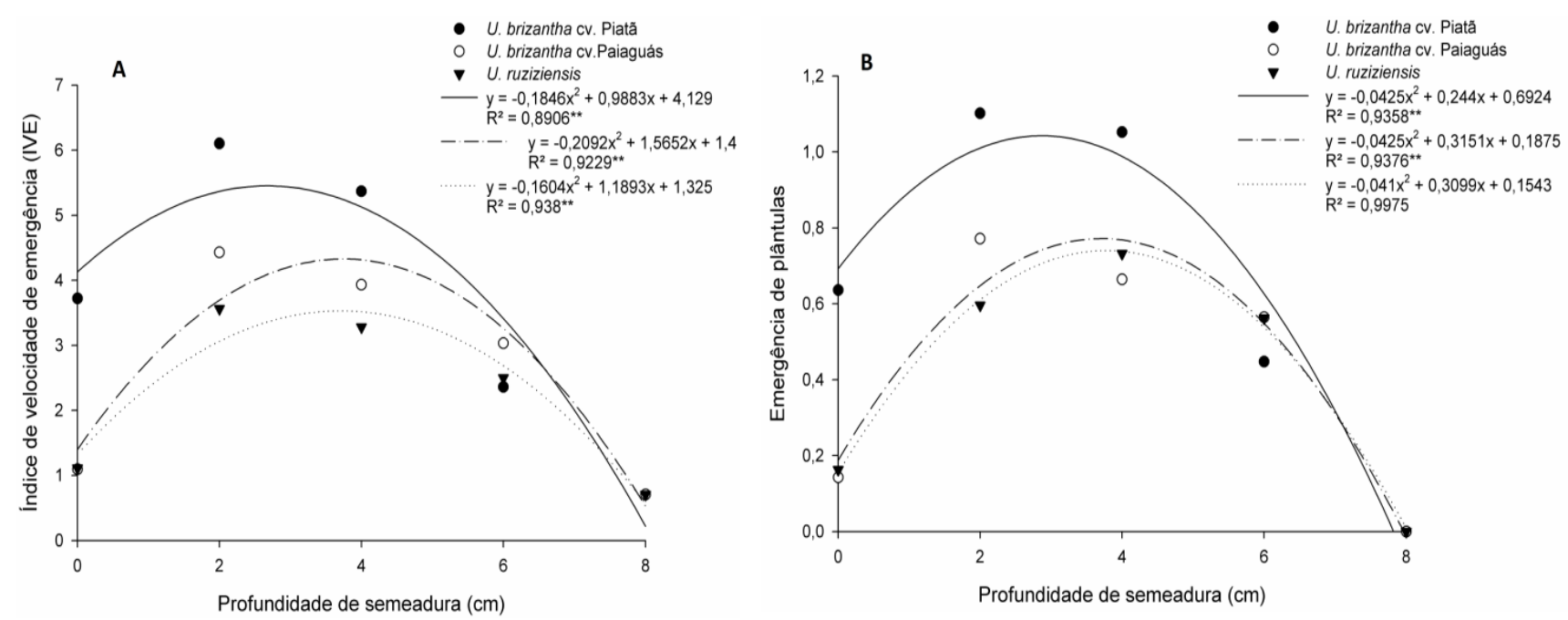

Figura 1. Índice de velocidade de emergência (A) e emergência de plântulas (B) de espécies de Urochloa em função da profundidade de semeadura. Ipameri-GO, 2014. 
Em todas as espécies avaliadas, quando semeadas a $8 \mathrm{~cm}$ de profundidade, não emergiram, demonstrando sua inviabilidade nessas condições.

Pacheco et al. (2010) trabalhando com crescimento inicial de braquiárias, observaram aumento no acúmulo de fitomassa verde e fitomassa seca das plântulas de braquiária até a profundidade de semeadura de $4 \mathrm{~cm}$. Resultados estes confirmados no presente estudo. No entanto, deve-se ressaltar que nestes estudos o solo utilizado foi peneirado, portanto, desestruturado, fator que pode ter facilitado a emergência das plântulas mesmo em profundidades maiores. A resistência mecânica à emergência das plântulas poderia ser maior em condições de campo, como reportado por Modolo et al. (2008). A produção de fitomassa das plântulas em estágios iniciais da cultura é importante, uma vez que, conforme mencionado por Portes et al. (2000), as braquiárias apresentaram crescimento lento, especialmente por possuírem metabolismo tipo $\mathrm{C}_{4}$ de fixação do $\mathrm{CO}_{2}$, característica que as fazem muito exigentes por luz. Portanto, quanto maior for a fitomassa seca produzida, maior foi a interceptação de radiação solar pela planta. Além disso, a produção de fitomassa é um dos principais fatores avaliados em plantas de cobertura direcionados para o sistema de ILP (PACHECO et al., 2008).

As braquiárias apresentam elevado crescimento radicular o que pode resultar em melhores condições de desenvolvimento durante o período de ausência de chuvas na entressafra (PACHECO et al., 2010).
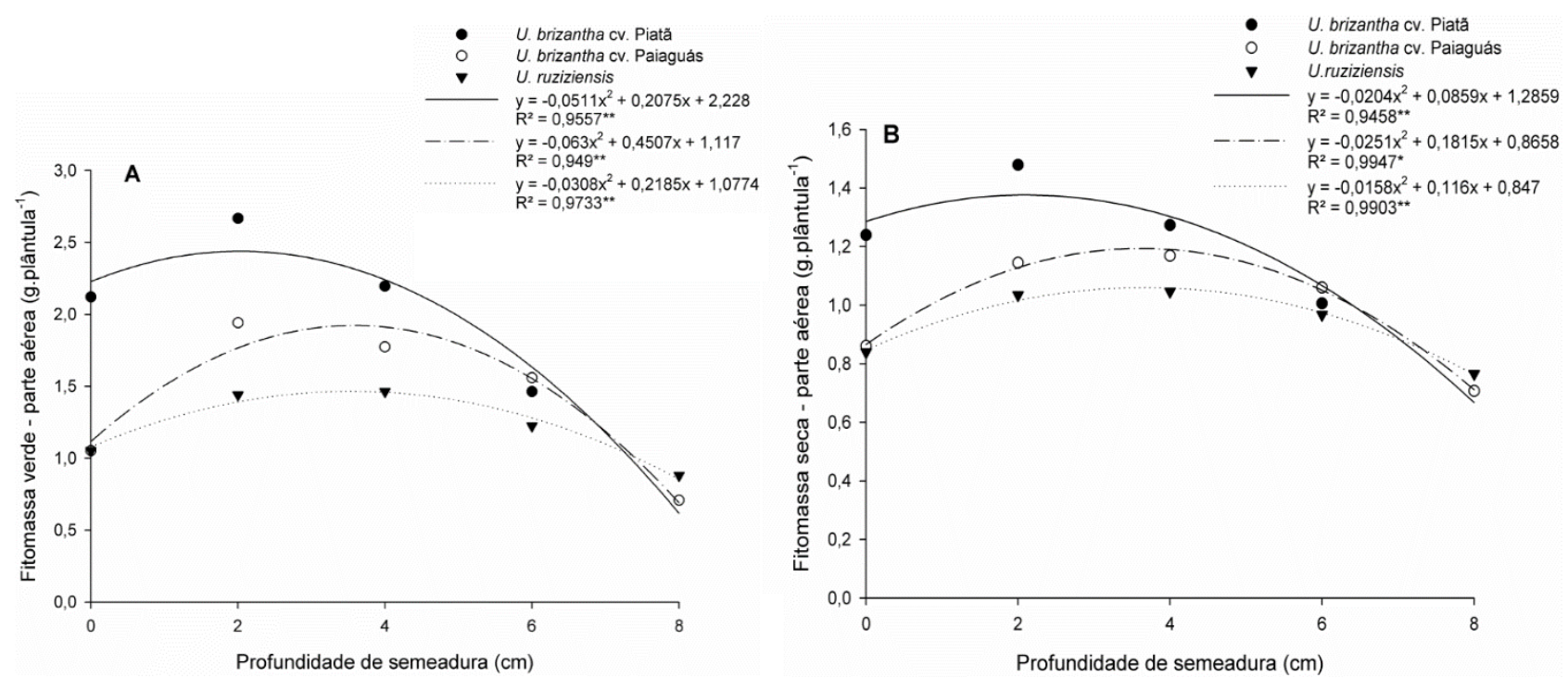

Figura 2. Fitomassa verde (A) e fitomassa seca da parte aérea (B) das espécies de Urochloa em função da profundidade de semeadura. Ipameri-GO, 2014.
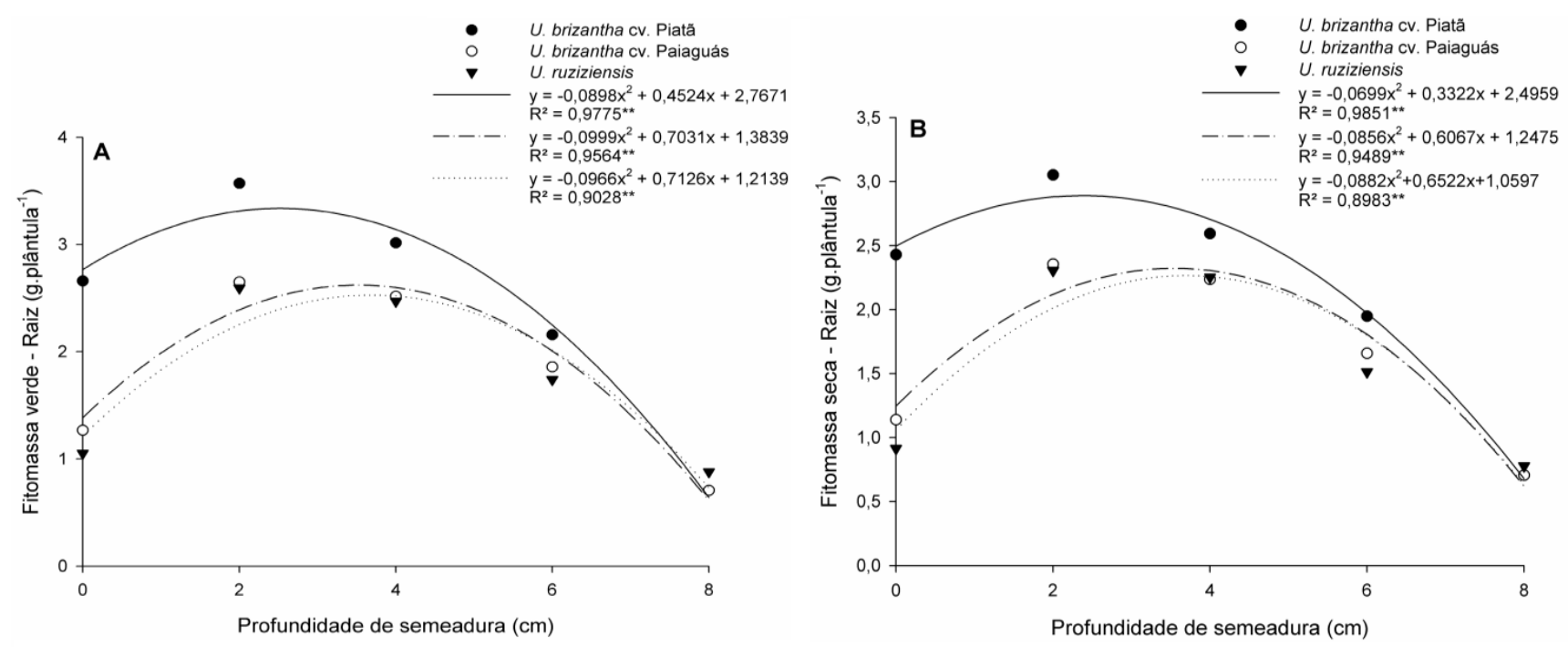

Figura 3. Fitomassa verde (A) e fitomassa seca (B) das raízes das espécies de Urochloa em função da profundidade de semeadura. Ipameri-GO, 2014. 
Para a produção de fitomassa verde das raízes (FVR) e fitomassa seca das raízes (FSR) das espécies avaliadas houve diferença significativa: $U$. brizantha $\mathrm{cv}$. Piatã apresentando maior FVR quando cultivada a $2,51 \mathrm{~cm}$, BRS Paiaguás aos $3,52 \mathrm{~cm}$ e o $U$. ruziziensis semeada a $3,69 \mathrm{~cm}$ (Figuras 3A).

A espécie $U$. brizantha cv. BRS Piatã apresentou maior produção de raízes quando semeada a $2,38 \mathrm{~cm}$ de profundidade. As profundidades de 3,54 e $3,70 \mathrm{~cm}$ mostraram-se superiores na BRS Paiaguás e na $U$. ruziziensis, respectivamente (Figura 3B). Nas demais profundidades, houve menor acúmulo de fitomassa seca das raízes devido à baixa emergência das plântulas nessas condições (Figura 1). Os resultados semelhantes foram obtidos por Pacheco et al. (2010). No entanto, Menezes e Leandro (2004) trabalhando com $U$. ruziziensis reportaram que o desenvolvimento da espécie foi sempre superior ou igual as demais plantas de cobertura quando semeada sobre a superfície do solo (sobressemeadura).

Pires et al. (2003) relataram que apesar dos benefícios decorrentes da presença da quantidade de raízes, em se tratando de plantas de cobertura, essa situação pode representar um fator de competição com a cultura comercial destinada a produção de grãos, justamente pela ocupação de maior espaço físico no solo e, consequentemente, maior extração de água e nutrientes. Em condições de restrição hídrica, situação típica das condições de $2^{\mathrm{a}}$ safra (FREITAS et al., 2013), na região do Cerrado, espécies com características mais agressivas podem ser prejudiciais à cultura consorciada.

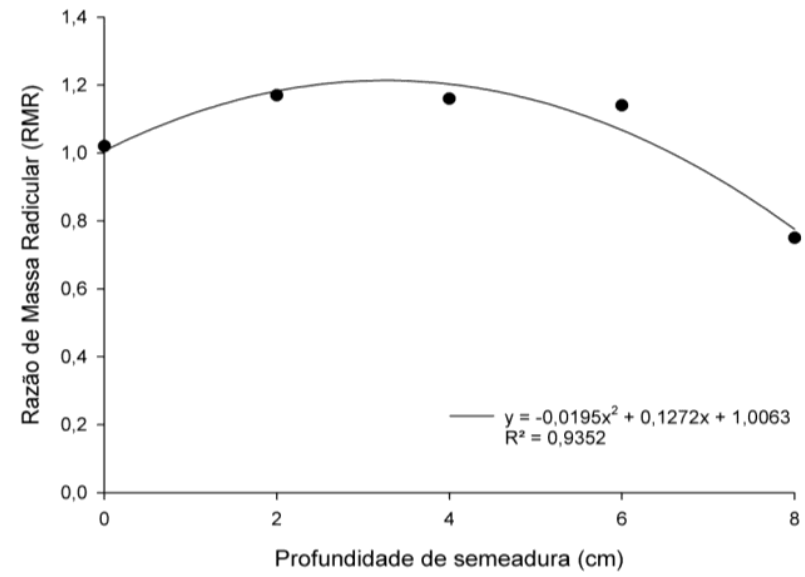

Figura 4. Razão de massa radicular (RMR) de espécies de Urochloa semeadas em diferentes profundidades. Ipameri-GO, 2014.

A razão de massa das raízes (RMR) apresentou diferença significativa somente entre as profundidades de semeadura das espécies forrageiras, não apresentando diferença entre as espécies (Figura 4). Os maiores valores de RMR foram obtidos quando as sementes foram semeadas a $3,26 \mathrm{~cm}$ de profundidade.
Próximo a essa profundidade foi onde ocorreu o maior índice de emergência de plantas, o que justifica a maior quantidade de raízes, uma vez que essas espécies apresentam raízes fasciculadas, o que lhe conferem uma grande densidade de raízes por planta.

A RMR está relacionada com a espécie em estudo, pois plantas que absorvem mais luminosidade tendem a apresentar um aumento na proporção raiz e parte aérea. Conforme Fini et al. (2010) e Kwak et al. (2011) isso ocorre devido à necessidade de uma maior contribuição na busca por água e nutrientes pela planta, sendo que o crescimento da parte aérea é dependente do suporte radicular (CORSI et al., 2001).

De acordo com Ferreira et al. (2006) há poucos estudos na literatura sobre o crescimento do sistema radicular quando comparados com aqueles relacionados com a parte aérea.

\section{Conclusões}

A profundidade de semeadura adequada para as espécies $U$. brizantha cv. Piatã, $U$. brizantha cv. Paiaguás e $U$. ruziziensis foi de 2,10, 3,61 e 3,67 cm, respectivamente, resultando em maior acúmulo de fitomassa seca das plântulas.

As espécies de forrageiras tropicais não se mostraram adequadas para a utilização em sobressemeadura $(0 \mathrm{~cm})$ e em semeaduras profundas $(8$ $\mathrm{cm})$.

\section{Referências Bibliográficas}

CAVARIANI, C.; NAKAGAWA, J.; VELINI, E. D. Mistura de fertilizantes fosfatados com sementes de Brachiaria decumbens Stapt Brachiaria brizantha (Hochst Ex A. Rich) Stapt. Revista Brasileira de Sementes, Pelotas-RS, v. 16, n. 2, p. 163-167, 1994.

CORSI, M.; MARTHA JR., G.B.; PAGOTTO, D.S. Sistema radicular: dinâmica e resposta a regimes de desfolha. In: Mattos, W.R.S. (Ed.) A produção animal na visão dos brasileiros. Piracicaba: Sociedade Brasileira de Zootecnia, 2001. p.838-852.

CRUSCIOL, C. A. C.; SORATTO, R. P.; BORGHI, E.; MATEUS, G. P. Benefits of integrating crops and tropical pastures as system of production. Better Crops International, Atlanta, v. 94, n. 1, p. 14-16, 2010.

DIAS-FILHO, M. B. Formação e manejo de pastagens. Belém-PA: Embrapa Amazônia Oriental, 2012. 9p. (Comunicado Técnico, 235).

FINI, A.; FERRINI, F.; FRANGI, P.; AMOROSO, G.; GIORDANO, C. Growth, leaf gas exchange and leaf anatomy of three ornamental shrubs grown under different light intensities. European Journal of Horticultural Science, Belgium, v. 75, n. 3, p. 111-117, 2010. 
FOLONI, J. S. S.; CUSTÓDIO, C. C.; POMPEI, F. P.; VIVAN, M. R. Instalação de espécie forrageira em razão da profundidade no solo e contato com fertilizante formulado NPK. Pesquisa Agropecuária Tropical, Goiânia-GO, v. 39, n. 1 , p. $7-12,2009$.

FREITAS, R. J.; NASCENTE, A. S.; SANTOS, F. L. S. População de plantas de milho consorciado com Urochloa ruziziensis. Pesquisa Agropecuária Tropical, Goiânia-GO, v. 43, n. 1, p. 79-87, 2013.

GARCIA, C. M. P.; ANDREOTTI, M.; TARSITANO, M. A. A.; TEIXEIRA FILHO, M. C. M.; LIMA, A. E. S.; BUZZETI, S. Análise econômica da produtividade de grãos de milho consorciado com forrageiras dos gêneros Brachiaria e Panicum em sistema de plantio direto. Revista Ceres, ViçosaMG, v. 59, n. 2, p. 157-163, 2012.

IKEDA, F. S. I; VICTORIA FILHO, R.; VILELA, L.; MARCHI, G.; CAVALIERI, S. D.; SILVA, A. A. Emergência e crescimento inicial de cultivares de Urochloa em diferentes profundidades de semeadura. Planta Daninha, Viçosa-MG, v. 31, n. 1, p. 71-78, 2013.

KWAK, M. J.; LEE, S. H.; WOO, S. Y. Growth and anatomical characteristics of different water and light intensities on cork oak (Quercus suber L.) seedlings. African Journal of Biotechnology, Grahamstown, v. 10, n. 53, p. 10964-10979, 2011.

MAGUIRE, J. D. Speed of germination aid in selection and evaluation for seedling emergence and vigor. Crop Science, Madison-USA, v. 2, n. 2, p. 176-177, 1962.

MENEZES, L. A. S.; LEANDRO, W. M. Avaliação de espécies de cobertura do solo com potencial de uso em sistema de plantio direto. Pesquisa Agropecuária Tropical, GoiâniaGO, v. 34, n. 3, p. 173-180, 2004.

MODOLO, A. J.; FERNANDES, H. C.; SCHAEFER, C. E. G.; SILVEIRA, J. C. M. Efeito da compactação do solo sobre a emergência de plântulas de soja em sistema plantio direto.
Ciência e Agrotecnologia, Lavras-MG, v. 32, n. 4, p. 1259$1265,2008$.

PACHECO, L. P.; PIRES, F. R.; MONTEIRO, F. P.; PROCÓPIO, S. O.; ASSIS, R. L.; CARMO, M. L.; PETTER, F. A. Desempenho de plantas de cobertura em sobressemeadura na cultura da soja. Pesquisa Agropecuária Brasileira, Brasília-DF, v. 43, n. 7, p. 815-823, 2008.

PACHECO, L. P.; PIRES, F. R.; MONTEIRO, F. P.; PROCÓPIO, S. O.; ASSIS, R. L.; PETTER, F. A. Profundidade de semeadura e crescimento inicial de espécies forrageiras utilizadas para cobertura do solo. Ciência e Agrotecnologia, Lavras-MG, v. 34, n. 5, p. 1211-1218, 2010.

PIRES, F. R.; SOUZA, C. M.; QUEIROZ, D. M.; MIRANDA, G. V.; GALVÃO, J. C. C. Alteração de atributos químicos do solo e estado nutricional e características agronômicas de plantas de milho, considerando as modalidades de calagem em plantio direto. Revista Brasileira de Ciência do Solo, Viçosa-MG, v. 27, n. 1, p. 121-131, 2003.

PORTES, T. A.; CARVALHO, S. I. C.; OLIVEIRA, I. P.; KLUTHCOUSKI, J. Análise do crescimento de uma cultivar de braquiária em cultivo solteiro e consorciado com cereais. Pesquisa Agropecuária Brasileira, Brasília-DF, v. 35, n. 7, p. 1349-1358, 2000.

RICHETTI, A. Viabilidade econômica da cultura do milho safrinha, 2012 em Mato Grosso do Sul. Dourados-MS: Embrapa Agropecuária Oeste, 2012. 8p. (Comunicado Técnico, 172).

VALLE, C. B.; EUCLIDES, V. P. B.; MONTAGNER, D. B.; VALÉRIO, J. R.; FERNANDES, C. D.; MACEDO, M. C. M; VERZIGNASSI, J. R.; MACHADO, L. A. Z. BRS Paiaguás: A new Brachiaria (Urochloa) cultivar for tropical pastures in Brazil. Tropical Grasslands - Forrajes Tropicales, Campo Grande-MS, v. 1, n.1, p. 121-122, 2013. 